José revueltas y el ser nacional mexicano: continuidades y mutaciones entre la novela y el ensayo | 343

\title{
JOSÉ REVUELTAS Y EL SER NACIONAL MEXICANO: CONTINUIDADES Y MUTACIONES ENTRE LA NOVELA Y EL ENSAYO
}

\author{
JOSÉ REVUELTAS E O SER NACIONAL MEXICANO: \\ CONTINUIDADES E MUTAÇÕES ENTRE O ROMANCE EO \\ ENSAIO
}

\author{
Solange Victory ${ }^{163}$
}

RESUMEN: Este trabajo se propone reflexionar acerca de la congruencia entre el proyecto político-intelectual del escritor mexicano José Revueltas tal como este se declara en sus ensayos teóricos y en su praxis militante- y sus novelas. Se partirá del diálogo polémico con aquellas interpretaciones que proponen una contradicción entre tales zonas del proyecto creador del autor. Esta problemática será abordada a partir de la lectura, el análisis textual y la comparación de El luto humano, novela de 1943, y "Posibilidades y limitaciones del mexicano", ensayo de interpretación histórica de 1950. Se hará foco en el modo en que en estos textos aparece, funciona y es puesto en tensión el discurso identificado con la corriente de pensamiento conocida como "filosofía de lo mexicano" o ensayo sobre el "ser nacional mexicano". Si bien la comparación superficial entre los textos arroja la ya estudiada contradicción entre novela y ensayo "político" que nos interesa analizar aquí, a través de la argumentación del artículo se concluirá por demostrar que tanto en ambos es posible leer una relación de tensión con la corriente de pensamiento conocida como filosofía de lo mexicano, aunque la crítica se emprende de modo diverso en cada género. De esta forma, se demostrará que es posible pensar en una coherencia o una unidad de índole superior entre ambas zonas textuales, unidad ya esbozada por el propio Revueltas a través del concepto de "realismo materialista-dialéctico" como eje para su escritura.

Palabras clave: José Revueltas; filosofía de lo mexicano; ensayo; novela; realismo.

\footnotetext{
${ }^{163}$ INDEAL-Facultad de Filosofía y Letras, Universidad de Buenos AiresUBA/CONICET
} 
RESUMO: Este trabalho pretende refletir a propósito da congruência entre o projeto político-intelectual do escritor mexicano José Revueltas tal como este afirma em seus ensaios teóricos e em sua práxis militante- e os seus romances. Partiremos do diálogo polêmico com aquelas interpretações que propõem uma contradição entre tais áreas do projeto criativo do autor. Este problema será abordado a partir da leitura, análise textual e comparação entre El luto humano, romance publicado em 1943, e "Posibilidades y limitaciones del mexicano", ensaio de interpretação histórica do ano 1950. O foco será colocado sobre a maneira em que nesses textos aparece, funciona e se tensiona o discurso identificado com a corrente de pensamento conhecida como "filosofia do mexicano" ou ensaio sobre o "ser nacional mexicano". Embora a comparação superficial entre os textos lance a já estudada contradição entre romance e ensaio "político" que nos interessa analisar aqui, através da argumentação do artigo, se concluirá por demonstrar que tanto no romance quanto no ensaio é possível ler uma relação de tensão com a corrente de pensamento conhecida como filosofia do mexicano, ainda que crítica se empreenda de modo diverso em cada gênero. Desta forma, será demonstrado que é possível se pensar uma coerência ou uma unidade de natureza superior entre as duas áreas textuais, uma unidade já esboçada pelo próprio Revueltas através do conceito de "realismo materialista-dialético" como eixo de sua escrita.

Palavras-chave: José Revueltas; filosofia do mexicano; ensaio; romance; realismo.

\section{Introducción: proyecto intelectual y literatura}

Los estudios críticos sobre la obra de José Revueltas han revisado con ahínco las numerosas dualidades que recorren los textos de este autor. Marxismo y cristianismo, marxismo y existencialismo, tierra y desarraigo, mundo letrado y universo campesino son algunas de las tantas polaridades que han sido abordadas en detalle como tensiones presentes y como motores narrativos de sus textos (Cf. PAZ, 1984; NEGRÍN, 1989; DABOVE, 2007). En la base de todas esas contradicciones, quizás incluso como su causa profunda, es también un lugar crítico muy transitado aquel que señala la incongruencia entre el proyecto político del autor, declarado explícitamente a través de sus crónicas y su extensa obra ensayística - pero sobre todo a través de su praxis política como militante, tanto del comunismo como de la izquierda no comunista, a lo largo de su vida - y la visión desencantada y pesimista del mundo que puede leerse en sus obras 
José revueltas y el ser nacional mexicano: continuidades y mutaciones entre la novela y el ensayo | 345 narrativas, novelas y cuentos de ficción, en visible tensión con el paradigma materialista histórico que rige el proyecto explícito del autor.

No es nuestra intención negar aquí la posibilidad de que la literatura bien pueda establecerse como un espacio de fuga con respecto a la voluntad del autor, incluso una zona donde sus convicciones ideológicas, estéticas y culturales más asentadas en el ámbito público tiemblan y entran en contradicción. No es necesario insistir sobre la posibilidad teórica de estas relaciones no armónicas entre la ideología de un autor y la ideología de su texto, cuyo abordaje puede ser considerado a partir de los desarrollos ya clásicos de Georg Lukács (1965) y Fredric Jameson (1989). ${ }^{164}$ Sin embargo, consideramos que en el caso de José Revueltas, tal falta de armonía parece, en principio, difícil de aceptar y merece una nueva discusión.

$\mathrm{Si}$, como lo indican las numerosas semblanzas que lo evocan (SANCHEZ REBOLLEDO, 2015; GONZÁLEZ ROJO ARTHUR, 2015), José Revueltas fue un epítome de la coherencia entre los principios y las acciones, un símbolo de honestidad y de rectitud humana, política y literaria, proponemos instalar una duda sobre la falta de unidad o la existencia de una contradicción entre sus textos -y su "credo"- "políticos" y sus obras "literarias". Porque, asimismo, la frecuente indicación acerca de la contradicción entre literatura y política en su obra obedece en última instancia a la misma lógica que en vida del autor permitió las

164 De Lukács (1965), se puede considerar como modelo de análisis su clásico estudio sobre Las ilusiones perdidas, de Balzac, donde el crítico demuestra cómo las imágenes que el texto balzaciano construye en relación con lo social se desprenden y superan la ideología conservadora del autor, habilitando la posibilidad de una contradicción entre la imagen subjetiva del mundo del creador y la autonomía de sus criaturas, que retratan el triunfo espiritual y material del capitalismo en la sociedad francesa. Por su parte, Fredric Jameson (1989) en su análisis de Lord Jim de Joseph Conrad concibe el proceso de textualización o la voluntad de estilo como un acto complejo, donde pueden coexistir materiales radicalmente diferentes -progresistas y reaccionarios- dentro de una misma obra. Jameson propone la aplicación de códigos mediadores entre lo social y el estilo, entre los que la causalidad como relación entre ambos espacios es tan solo una posibilidad entre otras, y los términos "ideológico" y "utópico" para señalar estas dos direcciones que pueden encontrarse tensionadas en la misma escritura. 
acusaciones del dogmatismo partidario y político contra sus novelas, frente al que Revueltas luchó incansablemente.

Siguiendo el razonamiento comenzado por estudios anteriores como el de José Manuel Mateo (2011, p.17-20) en En el umbral de Antígona, donde este autor se propone estudiar las interacciones entre reflexión estética y práctica narrativa en Revueltas partiendo de un debate con aquellos abordajes que proponen una inconsistencia entre la "estética asumida explícitamente" por el autor y la que "se desprende" de sus novelas, en este trabajo nos proponemos reflexionar acerca de la congruencia entre proyecto político del autor -tal como este se declara en ensayos de interpretación nacional, históricos y políticos- y sus novelas. Asimismo, partiremos del diálogo polémico con aquellas interpretaciones de la obra revueltiana que proponen una contradicción entre tales zonas del proyecto creador del autor.

Esta problemática será abordada a partir de la lectura y la comparación de El luto humano, novela de 1943, y "Posibilidades y limitaciones del mexicano", ensayo de interpretación histórica de 1950, poniendo el eje en el modo en que en estos textos aparece, funciona y es puesto en tensión el discurso identificado con la corriente de pensamiento conocida como "filosofía de lo mexicano" o ensayo sobre el "ser nacional mexicano". En tanto la reflexión sobre lo mexicano puede considerarse el paradigma hermenéutico hegemónico del México moderno -como se explicará en la siguiente sección-, se trata de un eje representativo para observar las posturas e intervenciones del autor sobre la historia y la política de su país. Por otro lado, la comparación superficial entre los textos arroja la ya estudiada contradicción entre novela y ensayo "político" que nos interesa analizar aquí. Mientras que en "Posibilidades y limitaciones...", el autor propone una crítica a los pensadores que buscan una especificidad de la psicología y la identidad mexicanas a través de un análisis histórico de la categoría de "mestizaje", El luto humano ha sido tradicionalmente interpretada como una novela imbuida de los giros y las ideas propias de las reflexiones sobre el ser nacional en pleno auge hacia los años cuarenta y cincuenta en México y en el resto de Latinoamérica. Incluso, Ruiz Abreu (2015, p.67) propone que "El luto humano [se] ha convertido [...] en la punta de lanza de otros escritores que vinieron después. Octavio Paz, amigo de Revueltas y su contemporáneo, escribió El laberinto de la soledad (1950) con la misma intención: describir el paisaje turbulento del alma nacional y llegar así a 
José revueltas y el ser nacional mexicano: continuidades y mutaciones entre la novela y el ensayo | 347

conocer su origen". ${ }^{165}$ Analizar en detalle estos presupuestos críticos, verificando su anclaje textual, nos ayudará a comprender el funcionamiento de esta aporía entre ensayo y novela en la escritura de Revueltas a partir del abordaje de un eje preciso en el que es posible observar su dialéctica.

Se propondrá en este trabajo que tanto en la novela como en el ensayo es posible leer una relación de tensión con la corriente de pensamiento conocida como filosofía de lo mexicano, aunque la crítica se emprende de modo diverso en cada género. El objetivo es demostrar, a partir de la comparación de los modos del ensayo y la novela tal como se expresan en estos textos pertenecientes a la obra de José Revueltas, que es posible pensar en una coherencia o una unidad de índole superior entre ambas zonas textuales, ya esbozada por el propio Revueltas en la defensa que, en su prólogo a la segunda edición de 1961 de su primera novela, Los muros de agua (1941), hace de la construcción de un "realismo materialista y dialéctico" (REVUELTAS, 1984, p. 20).

Antes de avanzar con el análisis textual del ensayo y la novela, y luego de una breve contextualización del corpus de textos seleccionados en el marco de la obra completa y la trayectoria intelectual de José Revueltas (apartado 2), repasaremos brevemente el campo de los estudios sobre el ser nacional en el México de los años cuarenta y cincuenta y situaremos al autor en los debates de este espacio, con el fin de comprender mejor las operaciones que se identificarán en los textos (apartado 3). Por razones de orden expositivo y a los fines de la argumentación, nos dedicaremos primero al estudio de "Posibilidades y limitaciones del mexicano" (apartado 4) y luego a El luto humano (apartado 5), aunque la novela sea cronológicamente anterior a la publicación del ensayo. Concluiremos con algunas reflexiones que se desprenden de la comparación de las obras (apartado 6).

165 Si bien en el artículo citado (2015, p.67) y en su excelente biografía sobre el autor (2014, p. 202) Álvaro Abreu Ruiz propone que El luto humano anticipa El laberinto de la soledad de Octavio Paz, en otra oportunidad (2010, p. 159) también señala el contraste entre la visión trágica de la Revolución Mexicana que José Revueltas construye con la que Paz diseña en su ensayo. 


\section{Entre el luto y la posibilidad}

A los textos elegidos para comparar en este trabajo los separan siete años. La distancia se agranda si tenemos en cuenta que la novela y el ensayo pertenecen, siguiendo la propuesta de Ruffinelli (1976, p.61-62), a dos "períodos" diferentes de la producción de Revueltas.

El luto humano fue la segunda novela publicada por el autor, en 1943. Con amplia aceptación entre la comunidad crítica e intelectual, la novela, sin llegar a ser un best seller, también tuvo éxito de público, dentro de las posibilidades del campo lector mexicano de los años cuarenta (ABREU RUIZ, 2014, p. 198). La recepción inmediata la percibió como una novedad dentro de la narrativa de tema nacional en México y, aunque algunos compañeros de partido la consideraron inadecuada por su perspectiva fatalista -Juan Almagre (1996a, p. 382), por ejemplo, la llamó "tratado de necrofilia espiritual"-, se trataba de una obra que todavía podía generar adhesiones entre las filas de intelectuales comunistas en las que José Revueltas se ubicaba. Este fue el caso de Enrique Ramírez y Ramírez (1996, p. 381) que a la par que amonestó duramente Los días terrenales, defendió El luto humano, diciendo que esta obra "acertó a captar la hondura y la grandeza del pueblo mexicano en su lucha contra la miseria".

"Posibilidades y limitaciones del mexicano" es un ensayo publicado en 1950, fruto de las preocupaciones del autor por la ontología del "ser" nacional impulsada por el grupo Hiperión. José Revueltas se ocupó de la problemática en diversos textos, hoy en día compilados en su mayoría en el volumen Ensayos sobre México (1985) de las Obras completas $\mathrm{n}^{\circ} 19$ de José Revueltas publicadas por Era y editadas por Andrea Revueltas y Philippe Cheron (NEGRÍN, 1996, p.277).

El ensayo fue publicado poco tiempo después de que Revueltas retirara de circulación la novela Los días terrenales (1949) y suspendiera la representación de la obra teatral El cuadrante de la soledad (1950) debido a los violentos ataques recibidos de parte del dogmatismo partidario comunista, que acusó a sus escritos de "destacar la tenebrosa selva de nuestra América negra, sin mostrar la salida hacia la luz" (NERUDA apud ANÓNIMO, 1996, p. 395), de "coincidir" con la filosofía sartreana (ALMAGRE, 1996a, p. 382) y de presentar al partido del proletariado como un "basurero moral" y al hombre como un "ser inmundo, sin salvación” (ALMAGRE, 1996b, p. 386). La viva polémica periodística que se agitó en torno a esta novela donde Revueltas realiza un devastador retrato de las internas del PCM durante su clandestinidad, seguida de la 
José revueltas y el ser nacional mexicano: continuidades y mutaciones entre la novela y el ensayo | 349 autocrítica del autor en 1950, marcan un antes y un después en su escritura y en su carrera intelectual. Por eso Ruffinelli (1976, p. 61-63) propone la división de la producción de Revueltas en dos momentos separados por la publicación de Los dias terrenales. Mientras que en la primera etapa -que abarca las novelas Los muros de agua y El luto humano y los cuentos de Dios en la tierra (1944)- la escritura de Revueltas aparecería, según Ruffinelli, como una praxis al servicio de la acción militante, dado que entonces el autor es aún un "hombre de partido", "sin contradicciones"; el segundo momento estaría diferenciado por el ingreso a su escritura de lo "conflictual político" como problema. Si bien consideramos crucial la autocrítica de 1950, sin embargo, creemos que "lo conflictual político" también está presente en el "primer" Revueltas, dado que, como el mismo Ruffinelli propone más adelante en su argumentación, ya El luto humano, por ejemplo, pone en tensión una visión sombría del hombre que contrasta con la doctrina estética zhdánovista, ${ }^{166}$ promulgada por el partido comunista y con la que, como veremos, también la escritura de Revueltas debe saldar sus cuentas (p.66).

Por lo tanto, se debe tener en cuenta que mientras El luto humano es previo a este gran quiebre que se produce en la carrera revueltiana, el ensayo es justo posterior al proceso de revisión al que hacia 1950 el autor se está sometiendo. ${ }^{167}$ Es decir que el ensayo se ubica en lo que podría

${ }^{166}$ Andréi Zhdánov fue un político soviético, miembro del Politburó y del Secretariado del Comité Central del Partido Comunista. Desde 1946, estuvo encargado de supervisar las actividades del Agitprop -o Departamento de Agitación y Propaganda del partido- cuya función era proteger la "pureza" ideológica de la cultura soviética bajo el mandato de los preceptos del realismo socialista, estética oficial del Estado desde los años treinta, que reemplazó los estilos "burgueses" anteriores a la Revolución de Octubre por formas de arte que se consideraban comprometidas con la representación admirativa de la vida de la clase proletaria y la difusión socialismo. El decreto Zhdánov fue la resolución del Politburó emitida el 10 de febrero de 1948 contra una ópera del compositor Vanó Muradeli, que dio inicio a una serie de persecuciones y críticas contra otros compositores soviéticos como Dmitri Shostakóvich y Serguei Prokófiev, muchos de los cuales posteriormente fueron presionados para formular arrepentimientos públicos.

167 Hacia el final de su vida, sin embargo, y luego de lo que algunos críticos identifican como un período de "reflujo" posterior a su 
pensarse como un momento de reformulación de algunas convicciones, políticas y estéticas, del autor. José Manuel Mateo (2011, p. 21-27) demuestra que, en términos estéticos, la autocrítica de 1950 no implicó en ningún momento una adhesión de Revueltas a los preceptos del "realismo socialista" ni una renuncia al realismo "materialista" y "dialéctico" como guía en su escritura. De la misma forma, podremos comprobar aquí que muchas de las críticas y tensiones que José Revueltas propone teóricamente en su ensayo de 1950 "Posibilidades y limitaciones..." sobre la problemática de la filosofía de lo mexicano, ya estaban contenidas en 1943 en El luto humano, a pesar de las zonas y fragmentos del texto aparentemente coincidentes con esta tendencia de pensamiento y sus ideas.

\section{Encuentros y desencuentros con una filosofía de época: José Revueltas y la reflexión sobre lo mexicano}

Hacia la década de 1940, cuando José Revueltas comienza a publicar, la reflexión profunda acerca de la esencia de la identidad nacional y la interrogación de las causas de la decadencia actual del país estaban todavía a la orden del día en una corriente de pensamiento que ligaba nación y ensayo. Por supuesto, este movimiento de "interpretación" ni era novedoso ni se limitaba a los confines mexicanos, sino que abarcaba una serie amplia, que recorría toda Latinoamérica, de "ensayos sobre el ser nacional".

Desde fines de los cuarenta hasta comienzos de los cincuenta, en México, la reflexión estuvo dominada por la actividad de un grupo de intelectuales conocido como Hiperión, nucleado en torno al profesor exiliado republicano José Gaos, a la Facultad de Filosofía y Letras de la UNAM y al Colegio de México. Entre sus principales miembros se encontraban Emilio Uranga, Luis Villoro, Jorge Portilla y Leopoldo Zea. El grupo se constituyó como una élite cultural a partir de una combinación de actividades de corte académico y de su presencia en los

autocrítica, expresado en sus novelas En algún valle de lágrimas (1956) y Los motivos de Cain (1957) (ESCALANTE, 1996, p. XXIX; REVUELTAS; CHERON, 1996, p. 325), tal proceso lo llevaría a ratificar sus convicciones de 1949 sobre la libertad artística a través de su novela Los errores (1964), donde vuelve a emprender una dura crítica al estalinismo (ESCALANTE, 1996, p. XXX). 
José revueltas y el ser nacional mexicano: continuidades y mutaciones entre la novela y el ensayo | 351

suplementos culturales más importantes del país. Además, fueron responsables de la creación de la colección "México y lo Mexicano", de editorial Porrúa, y de la fundación del "Centro de Estudios sobre el Mexicano y sus Problemas” (SANTOS RUIZ, 2015, p. 175).

Sin embargo, la interpretación nacional tenía en el ensayo y la filosofía mexicanos antecedentes notables. Por ejemplo, en el Ateneo de la Juventud, con las obras de Antonio Caso y de José Vasconcelos, que propusieron por primera vez la integración del indígena al progreso y la modernidad a través de la defensa del mestizaje, así como en el clásico El perfil del hombre y la cultura en México (1934), de Samuel Ramos, que postuló una interpretación de la inferioridad esencial del mexicano basada en el psicoanálisis freudiano y el determinismo positivista, con el fin de proponer su superación (RUIZ ABREU, 2014, p. 188-190).

El aporte del grupo Hiperión a esta tradición estuvo ligado a la apropiación en México, de la mano del ya nombrado Gaos y otros exiliados españoles, de nuevos paradigmas filosóficos, como la fenomenología alemana, la filosofía idealista (ESCALANTE, 2016, p. 105) y el existencialismo sartreano. Como explica Edith Negrín (1996, p. 277): "Al decir de Gaos, la actividad tendiente a elaborar una filosofía del mexicano pasó, con estos pensadores [los filósofos integrantes del grupo Hiperión] 'de una orientación preferentemente fenomenológicoesencialista [representada por Samuel Ramos] a una orientación preferentemente fenomenológico-existencialista' ". ${ }^{168}$ Puede decirse que es tal recepción crítica del existencialismo la que aproxima la obra de José Revueltas a las ideas de los Hiperiones dado que, como continúa Negrín (1996, p. 277): "De las actividades de los estudiosos que rodeaban a Gaos surgió una especie de atmósfera existencialista cuyas resonancias de alguna forma alcanzaron al joven Revueltas, si bien este autodidacta no formó nunca parte de la academia establecida".

En verdad, la relación de José Revueltas con la filosofía existencialista no fue homogénea a lo largo de toda su trayectoria. Sobre todo, tal vínculo sufrió modificaciones a partir de la polémica causada por

${ }^{168}$ Un ejemplo del modo en que los filósofos de Hiperión se apropiaron de algunas concepciones del existencialismo para pensar la condición de la filosofía latinoamericana puede leerse en el libro de Leopoldo Zea La filosofía americana como filosofía sin más (1969). 
Los días terrenales. ${ }^{169}$ Cabe recordar que fueron los elementos identificados como "existencialistas" en su texto los que despertaron una reacción más hostil de parte de los compañeros de partido del militante. Las relaciones entre el paradigma marxista y el existencialista han sido, históricamente, las de una constante polémica. El existencialismo representa para el marxismo un enemigo casi irreductible en tanto es, desde la visión del último: "la ideología de la burguesía decadente, utilizada magníficamente por los mercaderes de la guerra para envenenar a las masas y aplastar todo espíritu de lucha", como propone un artículo anónimo que, publicado en La voz de México, órgano del PCM, el 30 de julio de 1950, formó parte de la polémica en prensa sobre Los días terrenales (ANÓNIMO, 1996, p. 96). Sin embargo, más allá de las zigzagueantes declaraciones que Revueltas haya podido hacer y tener sobre esta filosofía a lo largo de su vida, muchos estudiosos de su obra coinciden en reconocer que el existencialismo, su concepción del ser humano y del mundo, están presente como núcleo generador en la narrativa de Revueltas (Cf. NEGRÍN, 1996; KOUI, 1996).

169 Un recorrido por la autocrítica y las opiniones del autor sobre el existencialismo es resumido por Andrea Revueltas y Philippe Cheron (1996, p. 325): "En un primer momento reacciona contra la crítica, pero poco después, frente al peso de la censura dogmática, empieza en él un proceso de autodenigración [...]. Es así como al responder a la acusación de existencialista, retoma los mismos argumentos dogmáticos para condenar esta corriente filosófica. Esta actitud va a ir cambiando poco a poco. En 1954, su opinión sobre el existencialismo es más matizada; sin embargo en 1955, al querer reingresar al PCM, vuelve a asumir su posición autocrítica. Más tarde, después del XX Congreso del PCUS (1956), su posición va a ir evolucionando hacia una reivindicación de la crítica asumida en Los días terrenales y hacia una revalorización de Sartre y del existencialismo. En 1964, frente a una pregunta expresa sobre existencialismo, afirma claramente su posición crítica hacia el estalinismo y el dogmatismo, que no abandonará hasta su muerte”. En 1960, Revueltas envía al propio Jean-Paul Sartre una carta personal con motivo de su visita a Cuba, donde le remite una copia de su "Carta de Budapest" (1957) y le plantea la urgencia de incorporar a los escritores latinoamericanos a la lucha contra el estalinismo, tarea en la que expresa considerarse solo (ESCALANTE, 1996, p. XXX). 
José revueltas y el ser nacional mexicano: continuidades y mutaciones entre la novela y el ensayo | 353

Además de lo que podríamos denominar esta "afinidad filosófica" general que vincula a Revueltas con los Hiperiones a través del existencialismo, el autor tuvo relaciones concretas con el grupo, con el cual interactuó e incluso sostuvo debates, como el que analizaremos aquí a través de su ensayo "Posibilidades y limitaciones...". Dos anécdotas relatadas por Leopoldo Zea con respecto a sus encuentros con Revueltas arrojan luz sobre algunos aspectos de esta relación. En 1951 Revueltas fue invitado a una serie de conferencias sobre el ser y la cultura del mexicano de las que participó también Leopoldo Zea y que, según este último, significaron la constitución formal del grupo Hiperión (ZEA, 1996, p. XXVI): ${ }^{170}$ "Revueltas fue invitado a dar una conferencia, lo que aceptó con mucho entusiasmo. Tartamudeó algunas palabras y, poniendo la cabeza sobre la mesa de la conferencia, empezó a dormir profundamente. No necesitaba palabras; la gente, sorprendida, le dedicó una ovación". Aunque la evocación de Zea es vaga, revela, sin embargo, el modo de participación efectiva pero lateral de Revueltas en los debates del grupo, como una presencia que, sin palabras, resultaba activa.

El segundo encuentro que Zea evoca se refiere a la aparición del escritor en sus clases de Filosofía de la Historia en la facultad para hablar acerca de la Revolución de Mayo en Francia y menciona el enfoque propio del autor sobre la interpretación de la historia de Hegel:

Respetuosamente, me preguntó sobre qué estaba hablando; le respondí que sobre la interpretación de la historia de Hegel. Le interesó mucho y me pidió continuase, para luego participar en las preguntas hechas por los estudiantes dando su propio enfoque a la historia y pidiendo a los estudiantes liberarse para poder liberar a su pueblo. (ZEA, 1996, p. XXVI)

${ }^{170}$ A pesar de esta declaración de Zea, la mayor parte de las referencias y los estudios sobre el grupo hacen constar su existencia entre 1948 y 1952 (DUSSEL; MENDIETA; BOHÓRQUEZ, 2009, p. 843). En todo caso, hacia 1951, fecha de las conferencias a las que Revueltas fue invitado, el grupo estaba en funcionamiento. 
En la misma línea, Enrique González Rojo Arthur (o Jr.), ${ }^{171}$ relata una elocuente escena acaecida en la fiesta de cumpleaños número ochenta de su abuelo, al que asistió como invitado Revueltas:

Rememoro con toda nitidez que Revueltas discutía apasionadamente, en el hall de la casa, con Jorge Portilla y Emilio Uranga, y no sé si con alguno más de los hyperiones, acerca del marxismo y el existencialismo. Recuerdo incluso la frase lapidaria con la que, entre sardónico y provocador, Pepe dio término al debate: 'lo que pasa con ustedes es que, aunque dicen hacer leído a Hegel, no entienden nada de dialéctica' (GONZALEZ ROJO ARTHUR, 2015, s/p).

Encontramos en estas evocaciones un señalamiento insistente que separa a Revueltas de las convicciones de Zea y otros representantes del Hiperión, y que se relaciona con su lectura personal de la filosofía de la historia y la dialéctica hegeliana. El análisis de este aspecto filosófico requeriría un desarrollo más extenso que, por cuestiones de espacio y de foco, dejaremos para otro trabajo. Baste por ahora con señalar con respecto a este punto, la propuesta de Alejandro Sánchez Lopera (2016, p.46), que destaca que la obra de José Revueltas propone un modo diverso de apropiarse de la historia hegeliana al no incurrir en el reclamo propio de la filosofía académica sobre la lectura de Hegel con respecto al lugar -o no lugar- de América en su historia universal.

Debido a esta ubicación descentrada o excéntrica de Revueltas en relación con el grupo Hiperión, entre los especialistas en su obra hay algunos que sugieren que sus textos son críticos con respecto a esta corriente de pensamiento (KOUI, 1996, p. 238), y una mayoría que considera que, por el contrario, estos tienen grandes influencias y similitudes con esta tendencia, en boga en su época, y que la representan (Cf. NEGRÍN, 1996; RUIZ ABREU, 2014; ESCALANTE, 1996). Por nuestra parte, consideramos que la pertenencia a un clima intelectual de época, caracterizado sobre todo por la apropiación crítica del paradigma

171 Enrique González Rojo Jr., hijo del escritor homónimo, ingresó a principios de 1956 al PCM y, junto a Eduardo Elizalde y a Joaquín MacGregor, formó parte de la célula Carlos Marx, la cual fue asignada a José Revueltas en 1956, luego de solicitar su reingreso al partido. Su abuelo era el poeta Enrique González Martínez. 
José revueltas y el ser nacional mexicano: continuidades y mutaciones entre la novela y el ensayo | 355 existencialista, junto a la preocupación en común por un núcleo de temas relacionados con la nacionalidad, la identidad y su desarrollo histórico, propios del momento, no implican, sin embargo, una congruencia total entre las posturas y desarrollos, tanto teóricos como literarios de José Revueltas y los del grupo Hiperión, que era el sector intelectual identificado con la interpretación nacional hacia el momento en que el autor estaba escribiendo.

Ante interrogantes similares a aquellos a los que se enfrentaban los filósofos de la interpretación mexicana, suscitados por iguales tensiones, propias del México del nacionalismo revolucionario, Revueltas propone respuestas diversas, filtradas por sus propias coordenadas políticoideológicas, que respondían al marco materialista-histórico (CARBALLO ROBLEDO, 2015, s/p) y que no eran, en este punto, las mismas que las del grupo Hiperión. La reprobación del comunismo como un producto del marxismo, que ya se encontraba en la obra tardía de Vasconcelos, fue continuada por las posturas de este grupo. José Gaos, su maestro, promovía la admiración a la filosofía hispanoamericana como una vía de liberación de América con respecto tanto al sometimiento al proyecto comunista como al capitalismo (SANTOS RUIZ, 2015, p. 127) y encontraba, de esta manera, una "tercera vía" en la polarización que planteaba la Guerra Fría, basada en la constitución de un Estado fuerte, que no recurriera, para solucionar los problemas propios, a "doctrinas exóticas" (p. 297). Una propuesta de este tipo está en las antípodas de las convicciones internacionalistas tanto de la teoría, como de la escritura literaria y la praxis militante de Revueltas.

Por otra parte, mientras que la filosofía de lo mexicano - tanto en su variante ateneísta como en la inflexión de los años cuarenta que aquí analizamos - fue en su mayor medida congruente con el nacionalismo revolucionario y funcional a su legitimación, puede decirse que el recorrido intelectual de José Revueltas se definió, por el contrario, en constante tensión con ese proyecto nacional. Como anteriormente lo había hecho el Ateneo de la Juventud, sobre todo a partir de la participación de Vasconcelos como Secretario de Educación Pública en el proyecto cultural de la Revolución hecha gobierno, también los Hiperiones contribuirían a legitimar el régimen revolucionario al dar un contenido filosófico al nacionalismo del partido oficial durante la década del cuarenta y comienzos de los cincuenta (SANTOS RUIZ, 2015, p. 443 444). Es por esta razón que en la introducción de este trabajo nos referimos a esta filosofía como paradigma hermenéutico hegemónico del 
México moderno, que se desarrolla no solo a comienzos y mediados del siglo XX, sino que se extiende, como mínimo, hasta la obra de Octavio Paz y algunas novelas de Carlos Fuentes.

Por el contrario, como propone Koui (1996, p. 241) con respecto a Los días terrenales - pero podríamos ampliar a toda la narrativa de Revueltas: "Si la orientación de esa novela hacia la conciencia y los problemas universales del hombre no admite ninguna duda", lo que para este crítico relacionaría al texto con la ontología de la mexicanidad y con la neutralización de la problemática social presente en la novela revolucionaria de los años treinta, sin embargo "el tratamiento que sufren en ella inicia el camino de la desmitificación de la estrategia de la burguesía nacional, enseñando la doblez de su discurso y de sus pretensiones hegemónicas, que se traducen por la enajenación de la clase obrera".

\section{4 "Posibilidades y limitaciones del mexicano": de la existencia de lo} nacional a sus condiciones materiales

El ensayo "Posibilidades y limitaciones del mexicano" (1950) se propone como una crítica expresa a los estudios que por aquellos años se planteaban la descripción de rasgos y caracteres típicos del "mexicano" y que, al hacerlo, daban por sentada su existencia. La enunciación del texto de Revueltas (1985) con respecto a este punto es terminante y acentúa su dimensión polémica:

Cuando los intelectuales y profesores pretenden definir al mexicano por su sentido de la muerte, por su resentimiento, por su propensión a la paradoja y por sus inhibiciones y elusiones sexuales, no están haciendo otra cosa que una literatura barata de salón. [...] Las características que se quieren hacer pasar como peculiares [...] forman una superficie cambiante, no sólo a lo largo de la historia, sino incluso a lo largo de la geografía. (p. 45)

Hablar de una particular "finura" del mexicano, o de que este tenga un privativo "sentimiento de rivalidad", del mismo modo que una "voz, gesto y silencio" o un "asombro", o una forma de sentir "lo imaginario y lo real", es tanto como pretender que ciertos fenómenos invariables y universales se expresen de una manera exclusiva y 
José revueltas y el ser nacional mexicano: continuidades y mutaciones entre la novela y el ensayo | 357 diferenciada (...) sobre un sujeto que en modo alguno es ni puede ser un sujeto exclusivo y diferenciado. (p. 41)

Por el contrario, este ensayo se propone demostrar que para que tal "absoluto" surgiera, fue necesario previamente un proceso histórico de constitución a través del cual "lo mexicano" llegó a convertirse en "lo nacional" o en el "ser nacional" de México. Tal proceso es el que este ensayo se dedicará a describir minuciosamente, en términos históricos y económicos.

La principal crítica que Revueltas formula a este tipo de estudios radica en lo que él considera una inversión de los factores de causa y efecto. Es decir, partir de lo psicológico o de lo espiritual para intentar explicar el desarrollo y el estado del país. En una profesión de fe materialista, el autor aplica un método determinista opuesto y supone que "un análisis correcto del hombre no puede sino tomar como punto de partida el análisis de las condiciones materiales de su existencia” (p. 45).

Teniendo en cuenta esta premisa metodológica, el autor procede a un recorrido histórico minucioso por diversos momentos de la evolución nacional haciendo foco en dos aspectos: la formación -y posterior integración - de la nacionalidad y la tenencia o propiedad de la tierra. El primer momento que desglosa es la Conquista, que expresa la transformación original de las relaciones de propiedad -el despojo de las tierras indígenas en manos de los españoles- y la consecuente contradicción que se produce entre las fuerzas productivas. A continuación, se analiza la Revolución de Independencia en 1810, la rebelión de Ayutla y las Guerras de Reforma, para finalmente llegar a la Revolución de 1910. En este desarrollo, Revueltas identifica el mantenimiento de las relaciones feudales de propiedad como causa de que los indios y mestizos de habla hispana, que ya desde la tercera fase de la Colonia, correspondiente a la instalación de los españoles en América, estaban llamados a ser los que integraran una nacionalidad mexicana, no pudieran hacerlo. La Revolución de 1910, última fase que analiza, crea las tan postergadas condiciones para la integración de la nacionalidad dado que transforma las relaciones de propiedad. ${ }^{172}$

172 Si bien en este y otros ensayos, el balance de Revueltas sobre la Revolución mexicana de 1910 es positivo, en otros textos el autor repudia la herencia de "la revolución burguesa consumida y agotada". Si por una parte, para Revueltas, como podemos apreciar en "Posibilidades y 
A lo largo de este recorrido, el ensayo propone una crítica histórica a la categoría de "mestizaje" como eje para pensar la nacionalidad -y en esto entra en clara polémica con el pensamiento tanto ateneísta anterior como el de los Hiperiones, que recuperaban la mezcla racial como factor positivo en la conformación nacional. En un procedimiento típicamente marxiano, "devela" el revestimiento ideológico de esa realidad que él define como económicamente determinada. Revueltas propone que el mestizaje se produce al asentarse el español en las tierras americanas mercedadas por la Corona. De esta manera:

[El] comercio sexual que antes estuvo desprovisto de contenido económico, ahora aparecía ligado a la propiedad de la tierra. Es aquí cuando nace el mestizaje, que ya no se realiza de una manera espontánea y fortuita, como pudo ser durante los primeros tiempos, sino bajo el imperativo de una necesidad económica improrrogable. (p. 49)

La necesidad desde entonces de que el indígena no muriera, dado que su destrucción suponía la desaparición de la mano de obra necesaria para explotar la tierra, opera como el factor económico debajo de los revestimientos ideológicos del mestizaje y de la evangelización como misiones de la Conquista en el Nuevo Mundo.

Al final del recorrido histórico, podemos observar cómo funciona el determinismo de este razonamiento:

limitaciones...", la Revolución mexicana significó la "gran oportunidad histórica" del México moderno, emparejada con la Revolución de 1917 en Rusia, sin embargo también desprecia la "transformación de la emergencia popular y obrera en una revolución democrático-burguesa (primero nacional-revolucionaria, [...] y luego revolucionariainstitucional)" a través de la política de instrumentalización y enajenación del proletariado por parte de la burguesía nacional (CARBALLO ROBLEDO, 2015, s/p). Tal balance de la Revolución Mexicana de 1910 puede hallarse, por ejemplo, en artículos como "Crisis y destino de México", a través del cual Revueltas respondió a "La crisis de México", de Daniel Cosío Villegas, de 1947, que constituyó una de los primeras intervenciones intelectuales en señalar el descontento ante los cambios y el rumbo que había tomado el país desde la Revolución (ALBURQUERQUE, 2014, p. 137). 
José revueltas y el ser nacional mexicano: continuidades y mutaciones entre la novela y el ensayo | 359

Después de este examen en que hemos visto las circunstancias y vicisitudes a través de las cuales el mexicano ha podido convertirse en lo nacional de México, resta detenerse en las contradicciones peculiares que ha llevado consigo dicho proceso de integración, contradicciones que al parecer constituyen aquello que otorga al mexicano una fisonomía propia (p. 56).

Es decir, para Revueltas, es lo que surge como contradicción a partir de este proceso lo que constituye o conforma esa fisonomía que la filosofía de lo mexicano pretende explicar. Revueltas sintetiza cuatro tipo de contradicciones emanadas de esta historia y estas condiciones materiales: a) diversidad de las nacionalidades unificadas durante la Conquista; b) constitución como nacionalidad oprimida a partir de las "armas" del conquistador; c) retraso histórico de la constitución del Estado Nación en 1810 y, finalmente; d) integración de la nacionalidad en 1910, cuando ya es necesario elegir entre las opciones históricas del imperialismo o el socialismo. Todas las demás expresiones de la realidad mexicana se hallan, según esta lógica, atadas a ser representaciones de estas cuatro contradicciones principales:

Estos cuatro grupos de contradicciones se reflejan en todos los demás aspectos de la vida mexicana. Es natural, por ejemplo, que la religión católica del mexicano sea una religión destinada a sustituir algo que se ha perdido y que ya no se sabe qué es. (p. 57)

Llegamos aquí a lo que consideramos el punto nodal de la argumentación del ensayo, dado que encontramos condensado en esta frase todo el planteo espiritual que El luto humano desarrolla in extenso sobre la religiosidad mexicana. Sin embargo, a diferencia de lo que se argumenta en los fragmentos teóricos o ensayísticos de la novela, en "Posibilidades y limitaciones...", tanto esta característica como otras correspondientes al mexicano y que cita a continuación -sentimiento de desposesión, actitud ante la vida y la muerte, etc. - están englobadas en una determinación material e histórica anterior, que las incluye y las explica: 
Todas estas características, sin embargo, se originan en circunstancias de carácter económico, sociológico e histórico, y están sujetas a transformación. Podríamos hablar de muchos otros rasgos psicológicos [...] pero lo que nos importa señalar aquí $[\ldots]$ son las posibilidades y limitaciones del mexicano.

[...]

Las limitaciones del mexicano, como se ha dicho, no son sino la consecuencia de su atraso histórico. Sin embargo, en las limitaciones del mexicano están sus propias posibilidades. (p. 58)

El final pone el acento en el futuro y en las posibilidades de cambio con respecto a las limitaciones determinadas por el desarrollo histórico antes descripto, donde, siguiendo la lógica revolucionaria del autor, podríamos concluir que entra en juego la cuarta contradicción identificada por el ensayo. Es decir, en sus propios términos, la elección entre el imperialismo -o la "extinción" - o el socialismo -o la "sobrevivencia" (p.57).

\section{El luto humano y el ser nacional}

Como se adelantó en la introducción, El luto humano ha sido una novela comúnmente asociada con las concepciones de la filosofía esencialista y existencialista de interpretación nacional, tanto anterior como posterior al texto. Relecturas del pasado prehispánico y colonial para comprender el presente posrevolucionario, momentos de análisis psicológico de los personajes campesinos junto a un fatalismo determinista, entre otras cosas, hacen que numerosos fragmentos de la novela coincidan con la enunciación propia de filósofos y pensadores identificados con esta corriente de pensamiento, como Samuel Ramos, Leopoldo Zea, Luis Villoro o, en años posteriores, con Octavio Paz y El laberinto de la soledad, considerado el cierre del ciclo de ensayos de interpretación nacional en México.

Los fragmentos del texto que avalan esta postura son numerosos y pueden aparecer, entre otros, en la enunciación focalizada en las reflexiones del personaje del cura del pueblo, referente de la pequeña comunidad que la novela describe. Por ejemplo, cuando los campesinos Adán y Úrsulo van a buscar al sacerdote para que este dé la extremaunción a la hija recién fallecida de uno de ellos, el cura piensa: 
José revueltas y el ser nacional mexicano: continuidades y mutaciones entre la novela y el ensayo | 361 Únicamente de oídas los conocía. Invulnerables y vivientes con su pasión terca corriéndoles por la sangre. "Y-pensó- si enemigos como son hoy se les ve juntos, no es sino porque tan solo han aplazado el odio para sustituirlo por esa convivencia silenciosa y sombría del país." Imposible concebir que alguna vez se tendieran la mano con verdadera lealtad o que alguna vez el contenido de las palabras cristianas se les revelase con su voz cálida (REVUELTAS, 1980, p. 23).

A partir de la crisis de conciencia que atraviesa -tópico tan caro a la literatura posrevolucionaria en autores como Juan Rulfo o Agustín Yañez y que transforma al sacerdote en un personaje particularmente afín a la introspección-, el cura desarrolla una teoría sobre México, sobre la comunidad nacional como una convivencia ilusoria y carente de solidaridad, y sobre la religión mexicana como una necesidad creada por la "orfandad" de dioses generada por la Conquista, entre otras cosas.

Además, en El luto humano las reflexiones sobre el ser nacional aparecen en las intervenciones del narrador en tercera o en las reflexiones de los otros personajes, intercaladas de modo casi inextricable con las intervenciones del narrador. Tal como sucede en la siguiente intervención del narrador en los pensamientos de Úrsulo:

Pero la gente era una gente humillada desde hacía muchos años y siglos; humillada desde su nacimiento, y la palabra más era tan solo para indicar que el criminal [...] seguiría matando [...]. Fatalidad pura, resignación triste y antigua, donde una apatía interior, atenta, inevitable y desolada, esperaba, sin oponerse, crímenes nuevos, más y más difuntos (p. 19).

En la cita anterior pueden identificarse operando tanto la concepción sobre el tiempo mítico primitivo, homogéneo y siempre igual, en contraste con las nociones modernas del acaecer histórico, como la melancolía campesina que Roger Bartra (2005) critica como parte constituyente del nacionalismo mexicano construido por una larga élite intelectual de pensadores. Por ejemplo, la supuesta pasividad, el ensimismamiento y la resignación del pueblo mexicano son características que ya Samuel Ramos (1951, p.36) atribuía al "egipticismo" del factor 
indígena: "No creemos que la pasividad del indio sea exclusivamente un resultado de la esclavitud en que cayó al ser conquistado. [...] Desde antes de la conquista los indígenas eran reacios a todo cambio, a toda renovación. [...] En el estilo de su cultura quedó estampada la voluntad de lo inmutable".

El carácter alegórico que casi todos los elementos de la trama adquieren también avecina esta novela a los procedimientos hermenéuticos propios de ensayos como El laberinto de la soledad o El perfil del hombre y la cultura en México. El nivel de complejidad filosófica e histórica que se desarrolla en estos fragmentos vuelve poco verosímil la construcción de algunos personajes, dado que difícilmente podría atribuirse tal complejidad a la introspección de un sujeto campesino del interior mexicano o a un cura de pueblo. A través de la intervención constante del narrador, los pensamientos de los personajes se homogeneizan en un registro lingüístico único, fuertemente alegórico y con momentos de alto vuelo lírico. Este tipo de intervenciones constituyen el nivel más "teórico" o "ensayístico" que frecuentemente se ha identificado y criticado en la novela como un defecto de construcción y de estilo.

A través de un relato donde casi todos los personajes y escenarios funcionan como símbolos, plagado de referencias bíblicas y precolombinas, El luto humano propone la reflexión en torno a dos problemas centrales, que también fueron preocupaciones nodales de la filosofía de lo mexicano: el origen y la religiosidad de la población. En cuanto al primer elemento, la novela elabora la teoría de un "génesis oscuro" para el pueblo mexicano. En el capítulo V, la problemática del origen se desarrolla en torno a la historia de vida de Úrsulo, que reflexiona sobre su nacimiento mestizo, hijo de una indígena y Don Vicente, señor hacienda y descendiente de españoles. La genealogía que se construye es híbrida, reúne evolución biológica (ciencia), creencias precolombinas ("la diosa de la obsidiana" Itzpapálotl, ${ }^{173}$ con la que Úrsulo identifica a su madre) y bíblicas (genealogía del patriarca Abraham) (Cf. p.

173 Fue una de las más importantes deidades de la cultura chichimeca y de la mitología azteca. Representaba el renacimiento y la regeneración y su poder se atribuía a las mujeres ancianas y sabias. Su aspecto hace referencia a una mariposa con alas de obsidiana. 
José revueltas y el ser nacional mexicano: continuidades y mutaciones entre la novela y el ensayo | 363 61-62). En cuanto a la religiosidad, el levantamiento cristero, ${ }^{174}$ que la trama de la novela evoca, representa en El luto humano el desarrollo de una fuerza oscura y elemental, un "arranque" de pura vida sin ideales ni convicciones claras, que pelea solamente por la vaga noción de la divinidad perdida, base de la espiritualidad nacional: "LLa violencia del levantamiento cristero] solo podía explicarse por la desposesión radical y terminante de que había sido objeto el hombre, que si defendía a Dios era porque en él defendía la vaga, temblorosa, empavorecida noción de sentirse dueño de algo" (p. 172).

Sin embargo, junto a este aspecto, puede postularse que en el entramado del texto existe, como yuxtapuesto y en contraste con los modos del discurso ensayístico coincidentes con la enunciación de la filosofía de lo mexicano que acabamos de describir, otro "sector" u otra "serie" discursiva que incorpora un horizonte diverso a la trama, otra atmósfera a la descripción, otra adjetivación y otro ritmo narrativo. Tal oposición entre "zonas" textuales se condensa a través de dos episodios que la historia de El luto humano presenta como polos de la historia que relata.

Se trata de dos momentos de "activación" del poblado y la sierra donde transcurre la trama, que representan dos posibilidades frustradas de esperanza de cambio o salida de la inercia provincial. La primera fase de dicha agitación es el acaecimiento de la Guerra Cristera en el pueblo, a cuyo relato accedemos mayormente a través de la conciencia del cura. Durante dicho enfrentamiento, Adán participa como sicario del gobierno

${ }^{174}$ La Guerra Cristera fue un conflicto armado civil que se produjo en México debido a un enfrentamiento entre la Iglesia y el gobierno revolucionario hacia mediados de los años veinte. Su causa principal fue la aparición de la "Ley Calles", sancionada por el presidente homónimo. Esta daba vigencia a la reforma de los artículos $3^{\circ}, 27$ y 130 de la Constitución de 1917, que limitaban el poder económico y político de la Iglesia. La ley encendió la ira inmediata del Arzobispo de México, del Episcopado y los laicos católicos. El levantamiento generado movilizó amplios sectores de la población de la zona centro oeste del país (Jalisco, Michoacán, Guanajuato, etc.), incluyendo a contingentes campesinos e indígenas. La revuelta se extendió en dos instancias armadas. La primera durante los gobiernos de Plutarco Elías Calles y Emilio Portes Gil, entre 1926 y 1929; y la segunda durante el de Lázaro Cárdenas entre 1934 y 1940. 
revolucionario, anticristero encargado de torturar y matar a sueldo enemigos políticos, más específicamente, a los jefes cristeros Guadalupe y Valentín. Tal actividad le gana la enemistad de la comunidad. El segundo episodio de reverdecimiento de la localidad se produce con la llegada de Natividad y del sistema de riego enviado por el gobierno revolucionario con el fin de producir el desarrollo agrícola de esa tierra "avara", "yerma" y "sin provecho" (p.26).

En ambos sucesos, el personaje de Adán, coaccionado por el gobierno, se establece como antagonista de las luchas que unifican a la comunidad. La Cristiada y la huelga por el sistema de riego se relacionan en la novela a partir de la participación de este personaje, y son descriptas como eventos de asociación y resistencia comunitaria a un gobierno federal que aparece ante el pueblo como un poder externo, que destruye las formas de vida autosustentables locales. Sin embargo, a la vez que espejadas y complementarias en el relato, ambas luchas revisten características opuestas.

La Cristiada aparece presentada desde varias perspectivas en el texto. La primera es la visión desalentada del cura del pueblo, personaje esquivo que representa una fuerte crisis de fe y de seguridad en su Dios. Para el cura, los "tiempos de la guerra" fueron tiempos llenos de odio, sangre y fuego (p. 77), donde la convicción religiosa cedió paso a algo "sucio y bajo": "Los rostros habían perdido devoción, profundidad. [...] Las viejas le besaban la mano otorgándole una dignidad ilegítima de jefe armado, de jefe sangriento, mientras los campesinos morían” (p. 77).

En el capítulo IX, El luto humano vuelve a narrarnos la Cristiada como "un periodo mucho más confuso, mucho más trágicamente confuso que otros" (p. 171), desde una nueva perspectiva -la de Adán- que, sin embargo, no es menos negativa que la del cura. Para el pequeño pueblecito a orillas del río, el levantamiento representa un brote de animación proveniente del centro del país:

Antes de que el Sistema fuese establecido, sin embargo, hubo en el pueblo cierta vida, para llamarla de algún modo. Por la noche circulaban sombras a través de la calle y en la iglesia reuníanse individuos extraños con el cura. Un misterio se desarrollaba como si hasta ese rincón de México llegara el soplo de algo grave y siniestro que estuviese ocurriendo en el país. (p. 168) 
José revueltas y el ser nacional mexicano: continuidades y mutaciones entre la novela y el ensayo | 365

Sin embargo, la vitalidad que despierta el conflicto religioso es una pobre y ciega expresión que contrasta con la fuerza de la huelga, cuyo vigor perdura aun luego de la muerte de Natividad, cuyo ataúd es acompañado por una multitud "inmortal" (p. 166) al cementerio y baja a la tumba "tal si hubiesen enterrado a una hoguera" (p. 180):

En el pueblecito la vida se levantó de pronto sobre sus propios pies, desatenta y brutal, como si a un enfermo se le hubiese sobrecargado algún cardiotónico activo y se revolviera sobre sí sin saber qué hacer con las manos, brincándole como resortes, ni con los ojos capaces de ver a través de la piedra. Nadie había comprendido las palabras del obispo de Huejutla ni las del delegado apostólico, que circulaban por todo el país, palabras que por otra parte no se habían escrito para ser comprendidas. Mas todos [...] levantáronse a una voz elemental, las raíces de cuyo sonido no tenían nombre siquiera. (p. 172)

Los cristeros son derrotados muy velozmente en el pueblo, a la primera entrada de federales y agraristas. Y poco antes de que la ciudad cayera en manos de los enemigos, el cura huye, aunque alcanza a ver como Adán asesina a Guadalupe.

Por el contrario, la huelga dirigida por Natividad es, al igual que su líder, un episodio descripto bajo los valores de la valentía, la fortaleza, la virilidad -considerada en el relato positivamente- y la nobleza de espíritu. La mirada de Adán, inmiscuido en el conflicto cuando lo envían a matar a Natividad, nos transmite esta perspectiva de los obreros parando:

Les salía al rostro la convicción profunda de su importancia y de su papel. Detenidos ahí con su empeño, eran la representación de la fuerza y de la voluntad colectivas: únicamente ese simple hecho de estar inmóviles bajo la roja bandera significaba la paralización absoluta de todo el trabajo en el Sistema de Riego. [...] [Adán] luchaba como contra un muro, pues era un muro todo esto, con la multitud ciega y terca que parecía inmortal (p. 116-117).

El mundo del trabajo, descripto como un acontecer "rítmico, armonioso", una "viril sinfonía", rumor vivo y alentador (p. 133) 
contrasta con el mundo confuso y raquítico de la espiritualidad y se perfila, de esta manera, como el nuevo credo que le dará esperanza a los hombres. Se puede creer que esta descripción de la huelga liderada por el "nuevo hombre" Natividad, que contiene todos los atributos optimistas y esperanzadores que alienta la doctrina del realismo socialista, podría haber sido aceptada e incluso festejada sin reparos por los compañeros de partido de Revueltas. Exaltación del proletariado en su trabajo, descripción de sus vivencias y de sus problemáticas con el fin de crear conciencia de clase en el lector y promulgar el socialismo son rasgos que pueden congeniar fácilmente con los fragmentos de El luto humano que focalizan en la huelga y en la labor como guía de Natividad. Dichos fragmentos contrastan fuertemente con las zonas del texto dedicadas a la introspección de corte existencialista y lúgubre de los personajes del cura, Adán y Úrsulo, entre otros.

Sin embargo, esto no implica que José Revueltas hiciera suyos los postulados estéticos soviéticos, siquiera en el período de "autocrítica" que atravesó luego de la polémica en torno a Los días terrenales. "Que hubo consignas para tratar de conducir a los creadores resulta innegable", argumenta José Manuel Mateo (2011, p. 27), "pero Revueltas no las adoptó ni siquiera lejanamente. [...] [Revueltas] establece claramente que los términos de la discusión deben ser estéticos, sin confundir doctrina con ideología". Su manera de acercarse a los postulados de la estética socialista parecen ser, de esta manera, los de la recuperación de su discurso y su puesta en relación con otras textualidades en el cuerpo de su novela, para que en ese diálogo en tensión se genere conocimiento sobre la realidad que busca describir.

Así pues, mientras que la Cristiada aparece como un episodio de ciego furor, ignorancia y abismo humano, la huelga se describe casi como una festividad plena de virilidad y vitalidad laboriosa. La lucha por la religión, guiada por poderes mezquinos y fuerzas irracionales, se opone a la lucha por los derechos sociales, motivo de esperanza en el progreso y nacimiento de una nueva forma de vida representada por Natividad.

Pese a sus diferencias, ambas luchas son derrotadas y la comunidad es dos veces vencida en sus intentos de defensa. Sin embargo, a diferencia de la derrota cristera, el final de la huelga no clausura completamente el futuro de liberación que prometía, dado que la muerte 
José revueltas y el ser nacional mexicano: continuidades y mutaciones entre la novela y el ensayo | 367 de Natividad "engendra" multitud, es decir, la posibilidad de su propia trascendencia en un cuerpo colectivo e "inmortal" (Cf. p. 114-117). ${ }^{175}$

De esta manera, puede decirse que en El luto humano la superación del discurso de la filosofía de lo mexicano no se da a través de una crítica teórica explícita, como sucederá en el ensayo de 1950, sino que se produce a partir de la yuxtaposición de los giros y el lenguaje propio de la interpretación nacional puestos junto a otro discurso, cercano al del realismo socialista, que aparece en la descripción del acontecer de la huelga de trabajadores como espacio de acción y cambio colectivo.

Observar este dialogismo o transtextualidad presente en la novela habilita a pensarla como un palimpsesto (GENETTE, 1989) de discursos y opciones narrativas sobre lo nacional y el pueblo mexicanos que Revueltas toma del sistema cultural de su época y aproxima en su texto, construyendo una visión compleja de la realidad que es propia de su modo dialéctico de concebir las cosas. De este modo, la novela deja de ser un bloque unívoco de sentido, caracterizado por una visión "pesimista" o "existencialista" de la historia mexicana y del país, enfrentado al "optimismo" del ensayo -que habilita frente a las limitaciones, las posibilidades-; y se transforma en un texto complejo, que expresa las tensiones, aporías y paradojas propias del modo de percepción del mundo revueltiano.

Apelando a la conceptualización propuesta por el ensayo de 1950, podríamos decir que mientras que en El luto humano las "limitaciones" del mexicano son explicadas a través de un discurso que echa mano a recursos propios de la filosofía de lo mexicano -como la apelación a una dimensión simbólica y mitológica en la construcción de los personajes, las referencias a la historia antigua mexicana o la circularidad narrativa que evoca una concepción circular de la temporalidad-, la "posibilidad" de superación de dichas restricciones se cifra en la serie textual que proponen los episodios de la huelga organizada por Natividad. Esta zona de la novela responde a una representación del trabajo acorde al realismo socialista y su clausura depende de la eliminación del líder positivo y de la posterior dispersión de la masa, llamada a encarnar la lucha.

\footnotetext{
${ }^{175}$ Si bien en El luto humano, novela temprana del autor, esta confianza en la capacidad de trascendencia por la vía política revolucionaria todavía está en pie, a medida que la obra de Revueltas evolucione en el tiempo, esta ilusión se irá erosionando.
} 
Hay en la obra de José Revueltas una visión compleja y fragmentada de la realidad concebida como conflicto a partir de cuya comprensión se puede acceder mejor a lo que parecen "contradicciones" entre las zonas de su obra. Como se propuso en la introducción, puede decirse que tal visión es sintetizada teóricamente por Revueltas en su prólogo a la segunda edición de 1961 de su primera novela, Los muros de agua (1941), donde el autor explica cuál es la concepción de "realismo materialista y dialéctico” que guía su escritura (REVUELTAS, 1984, p. 20). Opuesto en igual medida tanto al realismo "de reportero", es decir, al realismo que se somete "servilmente a los hechos como ante cosa sagrada", como al "realismo pletórico de vitaminas, suavizado con talco, gazmoño y adocenado, de los que a sí mismos se consideran 'realistas socialistas"' (p. 20); en este prólogo Revueltas define su literatura como un intento de aprehender el "lado moridor de la realidad" -o lado "agónico", en términos de Edith Negrín- que es aquel a través del cual el mundo permite ver el dinamismo de sus contradicciones (NEGRÍN, 1992, p. 859). Para este autor, la simplificación no tiene nada que ver con una concepción materialista-dialéctica de la estética (MATEO, 2011, p. 22). Él propone, por el contrario, una "selección" crítica de la realidad, una tipificación o una condensación operada por el realismo literario, que descarta de ella lo inútil (p. 26).

Producto de esta selección y de esta operación sobre la experiencia, el realismo propuesto por la escritura revueltiana oficiaría siempre como un espejo astillado, cuyos fragmentos difícilmente podrían unirse a la perfección, pero en cuyas grietas se revelaría con más verdad la complejidad del mundo que en cualquier otra mímesis más "armoniosa".

\section{Anotaciones finales}

Edith Negrín (1996, p. 277) propone que, aunque en “'Posibilidades y limitaciones del ser mexicano’ (1950), el autor se burla de los pensadores que pretenden hallar la especificidad del ser mexicano; no obstante, su obra narrativa se halla imbuida de esta tendencia". Si bien consideramos que hay mucho de acertado en esta afirmación, hemos intentado a lo largo de este artículo definir los modos específicos en que esa sugestión en relación con la filosofía de lo mexicano funciona en la obra de José Revueltas.

Una comparación superficial entre "Posibilidades y limitaciones del mexicano" y El luto humano arroja la ya estudiada dualidad entre el marxismo, que funge como marco teórico de análisis en el ensayo de 1950, y el existencialismo desencantado que rige la visión estética de la 
José revueltas y el ser nacional mexicano: continuidades y mutaciones entre la novela y el ensayo | 369 novela y que congenia con la visión propia de la filosofía de lo mexicano tal como se expresaba por entonces en las producciones de los intelectuales del Grupo filosófico Hiperión. Sin embargo, al profundizar en la construcción de los textos, hemos visto de qué forma en ambos existe una relación de tensión con la corriente de pensamiento sobre el ser nacional, a pesar de que la crítica se emprende de modo diverso en cada género. En la novela, la superposición de discursos, que habilita la intertextualidad y la presencia de zonas contrapuestas dentro de una misma obra, propone un modo de conocimiento de la realidad mexicana que surge de la propia tensión de "opciones" textuales. Por su parte, el ensayo comienza por la explicación de las limitaciones históricas y materiales del país para derivar de ellas no solamente las limitaciones de “carácter" y "sociales" del ser mexicano -su religión, su psicología y sus "atrasos"- sino, además, las "posibilidades" de que estas limitaciones puedan superarse. Es decir, el marxismo funge en él como marco teórico abarcador de la filosofía de lo mexicano, que solo cobra sentido cuando sus explicaciones sobre el ser nacional son concebidas como determinaciones de la historia material de México.

Reflexionar sobre la postura asumida por la escritura de Revueltas en relación con el paradigma filosófico del ser nacional mexicano colabora y se imbrica con la reflexión acerca del modo en que en su obra funcionan los paradigmas marxista y existencialista. Por un lado, porque muchos de los rasgos "existencialistas" presentes en El luto humano corresponden a las teorías y especulaciones sobre la nacionalidad que la novela postula, en diálogo con los interrogantes que por los mismos años se planteaba el Grupo Hiperión. Por otro lado, porque el marco teórico desde el que se critican dichas interpretaciones en el ensayo de 1950 y se las pretende superar es el marxista o materialista-histórico.

Se quiso demostrar, a través de la argumentación de este artículo y en la línea de estudios anteriores sobre el tema (NEGRÍN, 1989), que es posible superar esa aparente dualidad marxismo/existencialismo, que se reproduce en la oposición entre orientación pesimista de la estética novelística y optimismo militante del ensayo político. Dicha contradicción puede superarse a partir de la postulación de un campo semántico común entre ambos planos con centro en el concepto de desarraigo o desposesión, sobre el que tanto el ensayo como la novela se detienen. Si en el ensayo, Revueltas explica el proceso histórico mexicano a través de la desposesión material -las relaciones de propiedad, es decir, las relaciones del hombre con la tierra-; en la novela, se focaliza en la 
desposesión o el desarraigo espiritual: el abandono del hombre por Dios y su ser arrojado a la tierra en su ausencia -es decir, las relaciones del hombre con la divinidad-, dependientes de la primera. La trascendencia de ambos planos -desarraigo material y espiritual- se subsana, en el esquema teórico de Revueltas, por la vía política revolucionaria. Interpretados así, "marxismo" y "existencialismo" pueden concebirse como dos caras de una misma visión dialéctica del mundo que caracteriza la escritura de Revueltas.

\section{BIBLIOGRAFÍA}

ALBURQUERQUE G., N. E. Del desencanto a la crítica (Una aproximación a la querella entre Daniel Cosío Villegas y José Revueltas). In: ALFONSO, V. (comp.). El vicio de vivir: ensayos sobre la literatura de José Revueltas. México: Fondo Editorial Tierra Adentro, 2014.

ALMAGRE, J. El arte en México. In: REVUELTAS, J. Los días terrenales. Edición de Evodio Escalante. Buenos Aires: Colección Archivos/ALLCA XX, 1996a.

ALMAGRE, J. No se puede servir a dos amos. In: REVUELTAS, J. Los dias terrenales. Edición de Evodio Escalante. Buenos Aires: Colección Archivos/ALLCA XX, 1996b.

ANÓNIMO. Acerca de la declaración de Revueltas sobre su obra, publicado en La voz en México (órgano del PCM) 30 de julio de 1950, artículo no firmado. In: REVUELTAS, J. Los días terrenales. Edición de Evodio Escalante. Buenos Aires: Colección Archivos/ALLCA XX, 1996.

BARTRA, R. La jaula de la melancolia: identidad y metamorfosis del mexicano. México: Debolsillo, 2005.

CARBAllO ROBLEDO, I. La idea de México en José Revueltas. Interpretación desde el materialismo filosófico. In: NEGRÍN, E. et. al. Un escritor en la tierra: Centenario de José Revueltas. México: FCE, 2014, primera edición electrónica: 2015.

DABOVE, J.P. El bandidaje como experiencia de los límites de la razón letrada en José Revueltas. Revista de Crítica Literaria Latinoamericana, LimaHanover, año XXXIII, número 66, pp. 77-93, 2 semestre de 2007. Disponível em: <https://as.tufts.edu/romancestudies/rcll/pdfs/66/DABOVE.pdf>. Acesso em: 10 ago 2019. 
José revueltas y el ser nacional mexicano: continuidades y mutaciones entre la novela y el ensayo | 371

DUSSEL, E.; MENDIETA, E.; BOHÓRQUEZ, C. (eds.) El pensamiento filosófico latinoamericano, del Caribe y "latino" (1300-2000): historia, corrientes, temas y filósofos. México: Siglo XXI, 2009.

ESCALANTE, E. Circunstancia y génesis de Los días terrenales. In: REVUELTAS, J. Los días terrenales. Edición de Evodio Escalante. Buenos Aires: Colección Archivos/ALLCA XX, 1996.

ESCALANTE, E. Conjunciones y disyunciones en Octavio Paz y José Revueltas. Literatura Mexicana, v. XXVII, número 2, pp. 97-109, 2016. Disponível em: < https://revistas-filologicas.unam.mx/literaturamexicana/index.php/lm/article/view/923/

1009 >. Acesso em: 10 ago 2019.

GENETTE, G. Cinco tipos de transtextualidad; entre ellos, la hipertextualidad. In: GENETTE. G. Palimpsestos: La literatura en segundo grado. Madrid: Taurus, 1989.

GONZALEZ ROJO ARTHUR, E. Mi encuentro con Revueltas. In: NEGRÍN, E. et. al. Un escritor en la tierra: Centenario de José Revueltas. México: FCE, 2014, primera edición electrónica: 2015.

JAMESON, F. Leyenda y cosificación: Construcción de la trama y clausura ideológica en Joseph Conrad. In: . Documentos de cultura, documentos de barbarie: la narrativa como acto socialmente simbólico. Madrid: Visor, 1989.

KOUI, T. Los días terrenales, la novela de la herejía. In: REVUELTAS, J. Los días terrenales. Edición de Evodio Escalante. Buenos Aires: Colección Archivos/ALLCA XX, 1996.

LUKÁCS, G. Ensayos sobre el realismo. Buenos Aires: Siglo XXI, 1965.

MATEO, J.M. En el umbral de Antígona: notas sobre la poética y la narrativa de José Revueltas. México: Siglo XXI, 2011.

NEGRÍN, E. Arte y agonía en la narrativa de José Revueltas. In: CONGRESO DE LA ASOCIACIÓN INTERNACIONAL DE HISPANISTAS, X, 1989, Barcelona. Actas... Barcelona: PPU, 1992, pp. 853-860. Disponível em: < http://www.cervantesvirtual.com/obra/arte-yagonia-en-la-narrativa-de-jose-revueltas/>. Acesso em: 15 ago 2019.

NEGRÍN, E. El narrador José Revueltas, la tierra y la historia. Revista Iberoamericana, v. LV, número 148-149, pp. 879-890, julio-diciembre 1989. Disponível em: < https://revistaiberoamericana.pitt.edu/ojs/index.php/Iberoamericana/article/view/463 3/4797_>. Acesso em: 8 ago 2019. 
NEGRÍN, E. Los días terrenales a través del prisma intertextual. In: REVUELTAS, J. Los días terrenales. Edición de Evodio Escalante. Buenos Aires: Colección Archivos/ALLCA XX, 1996.

PAZ, O. Cristianismo y revolución: José Revueltas. In: . Hombres en su siglo y otros ensayos. Barcelona: Seix Barral, 1984.

RAMÍREZ Y RAMÍREZ, E. Sobre una literatura de extravío. In: REVUELTAS, J. Los días terrenales. Edición de Evodio Escalante. Buenos Aires: Colección Archivos/ALLCA XX, 1996.

RAMOS, S. El perfil del hombre y la cultura en México. Buenos Aires: Espasa Calpe, 1951.

REVUELTAS, A.; CHERON, P. Nota explicativa. In: REVUELTAS, J. Los días terrenales. Edición de Evodio Escalante. Buenos Aires: Colección Archivos/ALLCA XX, 1996.

REVUELTAS, J. El luto humano. México: Era, 1980.

REVUELTAS, J. Los muros de agua. México: Era, 1984.

REVUELTAS, J. Posibilidades y limitaciones del mexicano. In:

Ensayos sobre México. Prólogo, recopilación y notas de Andrea Revueltas y Philippe Cheron. México: Era, 1985.

RUFFINELLI, J. José Revueltas: Política y literatura (1941-1944). Revista de Crítica Literaria Latinoamericana, Centro de Estudios Literarios "Antonio Cornejo Polar"- CELACP, año 2, número 4, pp. 61-79, 1976. Disponível em: 〈https://www.jstor.org/stable/4529800〉. Acesso em: 19 ago 2019.

RUIZ ABREU, A. José Revueltas: escritura bajo presión. Revista de la Universidad de México, México, número 135, pp. 65-67, 2015. Disponível em:

<http://www.revistadelauniversidad.unam.mx/ojs_rum/index.php/rum/ article/view/16636/18774_>. Acesso em: 14 ago 2019.

RUIZ ABREU, A. José Revueltas: Los muros de la utopía. México: Cal y Arena, 2014.

RUIZ ABREU, A. Silencio y memoria de la revolución: Revueltas y Muñoz. In: OLEA FRANCO, R.; DE LA TORRE, L.A. Doscientos años de narrativa mexicana: Siglo XX. México: Colegio de México, 2010.

SÁNCHEZ LOPERA, A. José Revueltas y la filosofía latinoamericana: imágenes cinematográficas del mundo. Hallazgos, Bogotá, año 13, número 25, pp. 41-63, 2016. Disponível em: <http://www.scielo.org.co/scielo.php?pid=S1794$38412016000100003 \&$ script $=$ sci_abstract $\&$ tlng=es $>$. Acesso em: 8 ago 2019. 
José revueltas y el ser nacional mexicano: continuidades y mutaciones entre la novela y el ensayo | 373 SANCHEZ REBOLLEDO, A. Revueltas: la honestidad. In: NEGRÍN, E. et. al. Un escritor en la tierra: Centenario de José Revueltas. México: FCE, 2014, primera edición electrónica: 2015.

SANTOS RUIZ, A. Los hijos de los dioses: El grupo filosófico Hiperión y la filosofía de lo mexicano. México: Bonilla Artigas, 2015.

ZEA, L. Revueltas, el endemoniado. In: REVUELTAS, J. Los días terrenales. Edición de Evodio Escalante. Buenos Aires: Colección Archivos/ALLCA XX, 1996.

Recebido em: 23/08/2019

Aceito em: 14/09/2019 